\section{International Scientific Journal Theoretical \& Applied Science}

p-ISSN: $2308-4944$ (print) $\quad$ e-ISSN: 2409-0085 (online)

Year: $2018 \quad$ Issue: $06 \quad$ Volume: 62

Published: $30.06 .2018 \quad$ http://T-Science.org
Kamal Mirsahib Ibragimov candidate of economic sciences,

dissertant of the department

"Finance and financial institutions" Azerbaijan State Economic University,

Baku, Azerbaijan Republic

SECTION 31. Economic research, finance, innovation, risk management.

\title{
PROBLEMS OF RISK MANAGEMENT INFLUENCING FINANCIAL STABILITY IN INSURANCE COMPANIES
}

Abstract: The problems of managing risks that affect financial stability in insurance companies in modern conditions are examined in the article. The nature and essence of risks in the activity of insurance companies and financial markets are analyzed. Appropriate and systematic measures to minimize the various risks of insurance companies to ensure financial stability are considered. The importance of strengthening financial stability is substantiated, taking into account the possible risks of rendering insurance services and developing strategic management mechanisms for their elimination. A classification of insurance risks and their impact on insurance companies are prepared. The relative exposure of insurance companies to risks in practice is considered. A number of recommendations and suggestions on the problems of managing risks that affect financial stability in insurance companies are summarized and made.

Key words: risks of insurance activity, assessment of risks in insurance companies, risk management in insurance companies, financial stability in insurance company, risk management, financial stability of the insurer.

Language: Russian

Citation: Ibragimov KM (2018) PROBLEMS OF RISK MANAGEMENT INFLUENCING FINANCIAL STABILITY IN INSURANCE COMPANIES. ISJ Theoretical \& Applied Science, 06 (62): 264-268.

Soi: http://s-o-i.org/1.1/TAS-06-62-46 Doi: crossef https://dx.doi.org/10.15863/TAS.2018.06.62.46

\section{ПРОБЛЕМЫ УПРАВЛЕНИЯ РИСКОВ, ВЛИЯЮЩИХ НА ФИНАНСОВУЮ СТАБИЛЬНОСТЬ В СТРАХОВЫХ КОМПАНИЯХ}

Аннотация: В статье рассмотрены проблемы управление рисков, влияющих на финансовую стабильность в страховых компаниях в современных условиях. Анализированы характер и сущность рисков в деятельности страховых компаний и финансовых рынков. Рассмотрены адекватные и системные меры по минимизации разных рисков страховых компаний для обеспечения финансовой стабильности. Обоснована важность укрепления финансовой стабильности с учетом возможных рисков по оказанию страховых услуг и разработке стратегических управленческих механизмов по их устранению. Подготовлена классификация страховых рисков и их влияние на страховые компании. Рассмотрена относительная подверженность страховых компаний рискам на практике. Обобщены ряд рекомендаций и даны предложения по проблемам управления рисков, влияющих на финансовую стабильность в страховых компаниях.

Ключевые слова: риски страховой деятельности, оценка рисков в страховых компаниях, управление рисками в страховых компаниях, финансовая стабильность в страховой компании, риск-менеджмент, финансовая устойчивость страховщика.

\section{Introduction}

В современных условиях при периодически повторяющихся финансовых кризисах остро стоит вопрос системного управления экономическим рисками, в частности, рисками в страховых компаниях. Страховые компании при этом являются одновременно объектом и субъектом управления рисками, вследствие чего так важен эффективно организованный рискменеджмент с целью обеспечения финансовой устойчивости и надежности страховой компании в конкурентной среде. Так, страхование как экономическая категория - это система экономических отношений, которая включает в себя совокупность методов и форм создания и формирования целевых фондов денежных 


\begin{tabular}{|c|c|c|c|c|c|c|}
\hline Impact Factor: & $\begin{array}{l}\text { ISRA (India) } \\
\text { ISI (Dubai, UAE } \\
\text { GIF (Australia) } \\
\text { JIF }\end{array}$ & $\begin{array}{r}=1.344 \\
=0.829 \\
=0.564 \\
=1.500\end{array}$ & $\begin{array}{l}\text { SIS (USA) } \\
\text { PИHЦ (Russia) } \\
\text { ESJI (KZ) } \\
\text { SJIF (Morocco) }\end{array}$ & $\begin{array}{l}=0.912 \\
=0.207 \\
=4.102 \\
=\mathbf{2 . 0 3 1}\end{array}$ & $\begin{array}{l}\text { ICV (Poland) } \\
\text { PIF (India) } \\
\text { IBI (India) }\end{array}$ & $\begin{array}{l}=6.630 \\
=1.940 \\
=4.260\end{array}$ \\
\hline
\end{tabular}

средств с целью их использования для возмещения ущерба при возникающих рисках и в случаях оказания финансовой помощи гражданам при определенных событиях. По мнению ученого-экономиста И.Сиканевич, страхование является одним из стратегических секторов экономики вследствие того, что организация процесса жизнедеятельности невозможна вне создания и использования механизма компенсации потерь, произошедших из-за случайных событий. Так, в современное время страхование является финансовым стабилизатором экономики и дает возможность обеспечить компенсацию потерь и убытков, которые возникают в процессе общественного воспроизводства вследствие техногенных, социальных и природных катаклизмов без использования государственных ресурсов [1]. Из данных определений можно сделать вывод, что риск в системе страхования - это основополагающая категория, управление которой определяет место компании на страховом рынке и формирует ее финансовую устойчивость. Следует отметить, что финансовая устойчивость страховой компании характеризуется группами основных факторов. В обобщенном виде это: достаточный собственный капитал (уставное капитал, сформированный за счет прибыли резервный капитал и нераспределенная прибыль), страховые резервы, размещение активов и перестрахование [2].

\section{Materials and Methods}

Рассматривая определение понятия «риск» считаем целесообразным отметить трактовку Т.В.Журко Согласно его мнению, риск двумерная величина, которая характеризует вероятность и объем убытков, появляющихся вследствие неопределенности, сопровождающей деятельность организации [3]. Так, рассмотрим классификацию страховых рисков и их влияние на страховую компанию и относительную подверженность страховых компаний рискам, согласно оценке международной ассоциации страхового надзора (Рисунок 1, Рисунок 2). [4]:

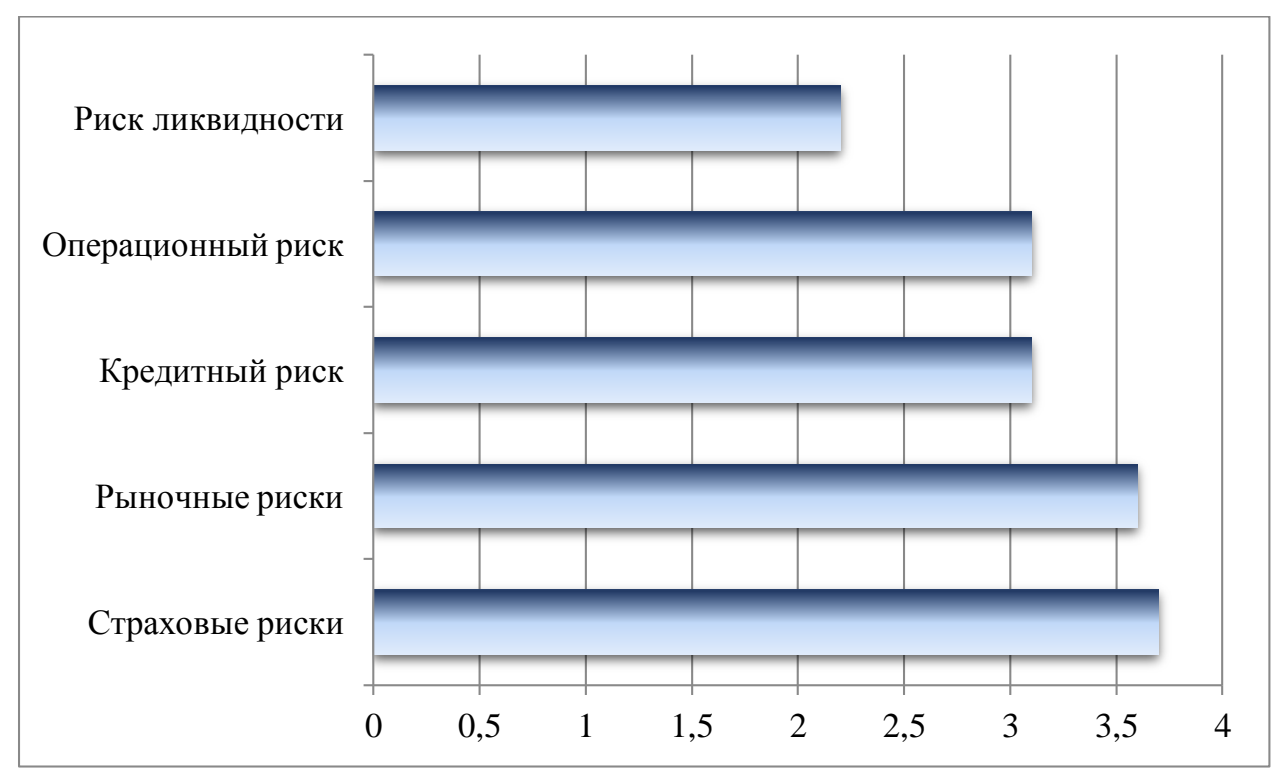

Рисунок 1. Классификация страховых рисков и их влияние на страховую компанию 


\begin{tabular}{l|lr|ll|ll} 
& ISRA (India) & $=\mathbf{1 . 3 4 4}$ & SIS (USA) & $=\mathbf{0 . 9 1 2}$ & ICV (Poland) & $=\mathbf{6 . 6 3 0}$ \\
Impact Factor: & ISI (Dubai, UAE) & $=\mathbf{0 . 8 2 9}$ & PUHL (Russia) & $=\mathbf{0 . 2 0 7}$ & PIF (India) & $=\mathbf{1 . 9 4 0}$ \\
& GIIF (Australia) & $\mathbf{0 . 5 6 4}$ & ESJI (KZ) & $=\mathbf{4 . 1 0 2}$ & IBI (India) & $\mathbf{4 . 2 6 0}$ \\
& JIF & $=\mathbf{1 . 5 0 0}$ & SJIF (Morocco) & $=\mathbf{2 . 0 3 1}$ & & \\
\hline
\end{tabular}

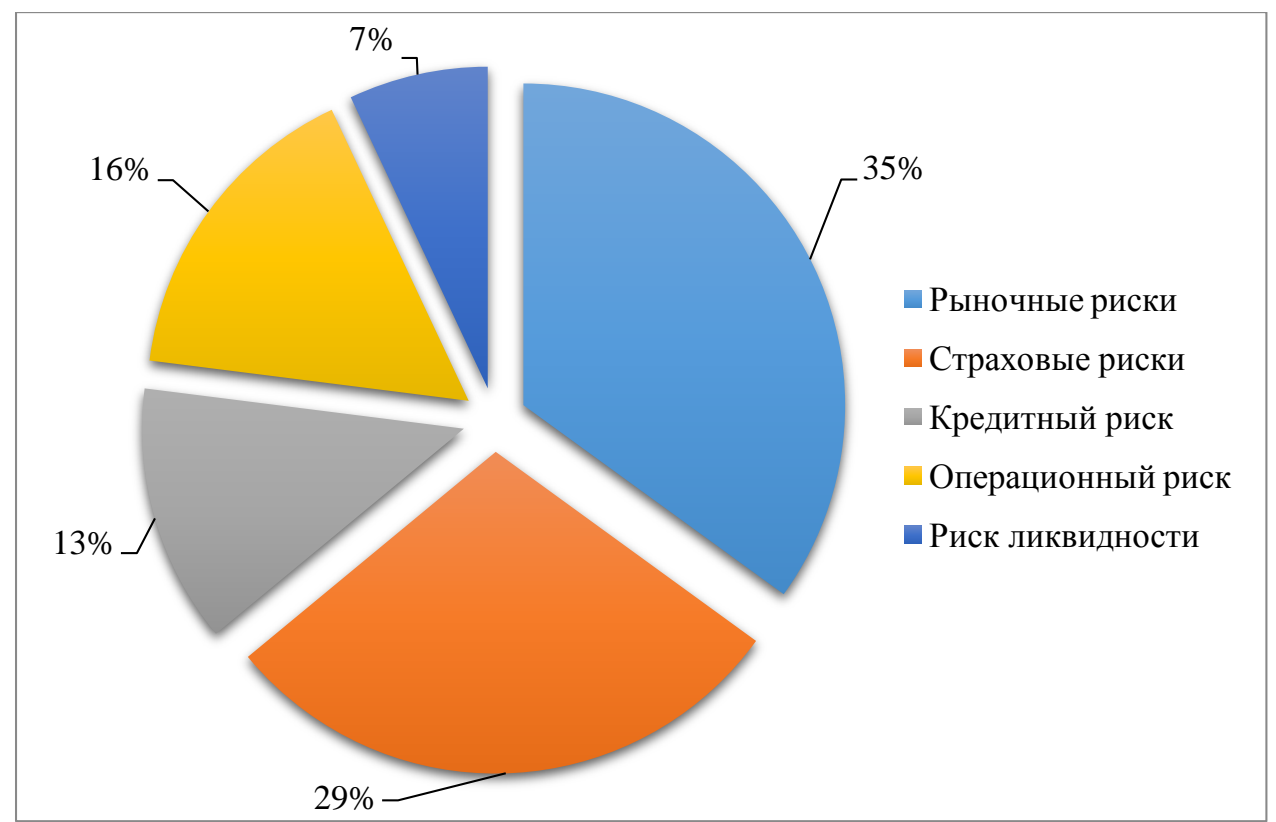

Рисунок 2. Относительная подверженность страховых компаний рискам (сайт IAIS).

Так, как видно из Рисунка 1 и Рисунка 2, риски для страховых компаний можно классифицировать в следующие: рыночные риски, страховые риски, кредитный риск, операционный риск и риск ликвидности. Рассмотрим их более подробно:

$\checkmark$ рыночные риски - отрицательное изменение стоимости активов и пассивов страховой компании, подверженной рыночным изменениям.

$\checkmark$ страховые риски - это риски вероятных потерь и убытков в случае неправильно выбранной стратегии по принятию и оценке рисков на страхование. Эта группа рисков делится, в свою очередь, на риск андеррайтинга (принятие для страхования нецелесообразных рисков или ошибка в выборе объекта страхования), риск снижения технических резервов (технические резервы - создаются из взносов страхования с целью выполнения компанией своих обязательств по договорам) и риск катастроф.

$\checkmark$ кредитный риск - риск вероятных убытков вследствие невыполнения другой стороной своих обязательств.

$\checkmark$ операционный риск - риск отказа внутренних систем, процедур и систем контроля, риск аварий, приводящие к финансовым убыткам компании.

$\checkmark$ риск ликвидности - это риск убытков, возможных в ситуации, когда для удовлетворения требований по своевременным выплатам в наличии страховой компании окажется недостаточно активов.

Изучая классификацию рисков и числовые характеристики отдельных рисков, следует отметить, что наиболее часто встречающиеся методы оценки различных рисков являются показатели Value at Risk (VaR) и Expected Shortfall (ES). VaR характеризует убытки в течении определенного заданного периода времени, которые не будут превышены с заданной вероятностью [5].

В управлении рисками, которые влияют на финансовую стабильность в страховой компании, основополагающая роль принадлежит страховщику и финансовой устойчивости его деятельности. Так, отмечается, что финансовая устойчивость страховщика - это его способность своевременно выполнять взятые на себя обязательства по договорам страхования при изменении экономической конъюнктуры и влиянии неблагоприятных факторов [6]. С помощью деятельности страховщика концентрируются значительные финансовые резервы в его руках, активно использующиеся в инвестиционном процессе. В свою очередь, надежность и эффективность размещения временно свободных денежных средств влияет на доходы страховщика и его платежеспособность. Отметим, что страховая компания как финансовый институт подвержена негативному влиянию рисков с двух сторон: с одной стороны, в процессе различных видов деятельности, в частности, инвестиционной, со стороны страховщика возникают финансовые риски, которые связаны с невозвращением инвестированных средств или неполным получением прибыли, с другой стороны, страховые компании подвержены так называемым «чужим рискам», т.е. риски, передающиеся посредством различных договоров страхования или перестрахования [7]. Здесь одним из наиболее методов управления рисками 
изменения финансовой стабильности страховщика в страховой компании является перестрахование, в основе которого лежит система перераспределения риска между страховщиками. Т.е. при перестраховании страховая компания, которая принимает на страхование риски, часть своей ответственности по ним предает на взаимообговоренных условиях другим страховщикам [8]. Отметим так же, что страховщик обязуется выполнять условия, которые должны быть исполнены в течение длительных сроков (например, пенсионное страхование) или которые определяются с помощью теории вероятности (страхование автотранспортных средств, страхование последствий несчастных случаев и др.). Именно вследствие этого столь большое значение имеют факторы платежеспособности страховых компаний и обеспечения их финансовой устойчивости. Причем эти понятия существенно различаются между собой. Так, платежеспособность страховой компании - это ее способность полностью и своевременно выполнять финансовые обязательства, взятые на себя. Финансовая же устойчивость - это способность страховой компании в течение всего срока ее действия сохранять платежеспособность по страховым договорам в соответствии с внутренними и внешними условиями [9].

Что же касается нейтрализации разных рисков, появляющихся в процессе деятельности страховой компании, то здесь первостепенное значение отводится внутреннему рискменеджменту. Так, понятие риск-менеджмент представляет собой комплекс мер, которые направлены на общее выявление, управление и искоренение действий различных рисков, препятствующих здоровому функционированию страховой компании [10].

Далее рассмотрим взгляды ученыхисследователей на оценку, управление и механизмы снижения влияния рисков на финансовую платежеспособность и устойчивость страховой компании в современной конкурентной среде. Так, Яранцева Е.А. в своих трудах исследовала методы оценки рисков, которые воздействуют на финансовую устойчивость страховых компаний. Ученый отмечает, что регулятор страхового рынка на сегодняшний день обладает небольшим инструментарием для контроля за показателями финансовой устойчивости страховой компании. В частности, он включает в себя 3 основных фактора: 1) контроль за правильностью создания резервов страхования; 2) контроль за соблюдением соотношения имеющихся в наличии средств и принятых на себя обязательств; 3) требования к структуре и составу активов, которые принимаются для погашения средств страховых резервов и страховщика [11]. Другой исследователь, изучая вопросы комплексного управления рисками в страховых организациях, отметил, что в случае финансового риска возможны 2 исхода - положительный (дополнительный доход, прибыль и др.) и отрицательный (убытки, потери, ущерб и др.) и целями управления рисками в страховой компании являются минимизация отрицательного и максимизация положительного эффекта реализации риска [12]. Изучая эти же вопросы, исследователь Гуштеров Д.Х. пишет, что усложнение рисковой ситуации обуславливает трансформацию механизмов риск-менеджмента. Так, в современных условиях риск не рассматривается как фрагментное негативное явление, а как неизбежный атрибут внешней среды. Следовательно, деятельность компании осуществляется в условиях глобальной финансовой неопределенности, причем устраняя одну неопределенную ситуацию, компания сталкивается с группой новых неопределенных ситуаций [13]. Рассматривая методологию управления финансами страховой системы, Морозко Н.И. утверждает, что недостаточная стабильность и динамичность развития страхового рынка - это следствие недостаточного уровня капитализации страховых компаний и неимением эффективного инструментария для создания надежной финансовой стратегии, которая создает условия для рационального управления денежным потоком, формирования надежной структуры капитала и др. [14]. В трудах других ученых-исследователей (Финогенова Ю.Ю., Задоянный А.А. и Бахчеева М.Н.) исследованы вопросы страхового рискменеджмента персональных инвесторов, аспекты контроля платежеспособности в системе финансового мониторинга страховых предприятий и критерии механизма снижения финансовых рисков промышленного предприятия при формировании страховой защиты. Так, отмечается, что страховой риск-менеджмент персонального инвестора характеризуется созданием мотивации к приобретению инвесторами страхового покрытия, которое обеспечит защиту от рисков в долгосрочной перспективе [15]. Что касается финансового контроля финансовой стабильности страховой компании, то здесь важное значение отводится бизнес-аудиту как методу исследования и оценки платежеспособности страховой компании и др. [16]. Отметим так же, что управления рисками страховой компании затрагивает все направления ее деятельности, как тактические, так стратегические, так и операционные. Следовательно, управление рисками должно иметь комплексный и целенаправленный характер и ориентироваться на улучшение 
финансовой прочности и устойчивости компании на рынке страховых услуг [17].

\section{Conclusion}

Таким образом, обобщая все вышесказанное, можно отметить ряд выводов по управлению рисков, влияющих на финансовую стабильность в страховых компаниях:

$\square$ для успешного управления рисками компании необходимо разработать и внедрить концепцию финансового мониторинга страховой компании с учетом внутренних и внешних факторов; требуется создание организованной и надежной системы риск-менеджмента для противостояния неопределенности страхового рынка;

$\square$ имеется необходимость в повышении уровня капитализации страховой компании и создании соответствующего инструментария с целью создания надежной финансовой стратегии;

$\square$ и, наконец, необходим комплексный анализ конъюнктуры страхового рынка с целью своевременного реагирования изменениям его и возникающим рискам в современных условиях и др.

\section{References:}

1. Sikanevich I. (2009) Finansovaja stabil'nost' strahovogo sektora.// Zhurnal «Bankovskij Vestnik», 2009.- p. 35-42.

2. Serikova G.S. (2012) Faktory obespechenie finansovoj ustojchivosti strahovyh kompanij.// Zhurnal «Sovremennaja nauka: Aktual'nye problemy teorii i praktiki», №1, 2012.

3. Zhurko T.V. (2008) Mery po snizheniju riskov strahovyh kompanij /// Audit i finansovyj analiz. 2008. №2. -p.280-284.

4. Sjaak Bouma (2006) Capgemini's Compliance and Risk Management Centre of Excellence. Risk Management in the Insurance Industry and Solvency II. European Survey - 2006. http://www.capgemini.com.

5. Nazarova V.V., Matveeva E.A. (2014) Koncepcija risk-menedzhmenta v strahovyh organizacijah// Nauchnyj zhurnal NIU ITMO. Serija «Jekonomika i jekologicheskij menedzhment», №4, 2014.- p. 258-275.

6. Shnurova L.K. (2015) Analiz i kontrol' finansovoj ustojchivosti strahovshhika.// Zhurnal «Jekonomika i upravlenie», №1(3), 2015.- p. 51-59.

7. Kazak Ju.A., Slepuhina Ju.Je. (2010) Finansovye riski v strahovom biznese: modeli i metody ocenki. 2010.

8. Karpickaja M.E., Krupenko Ju.V. (2018) Perestrahovanie kak instrument obespechenie ustojchivosti strahovoj organizacii. http://www.edos.bsue.by

9. Kasymova A.G. (2010) Faktory, opredeljajushhie finansovuju ustojchivost' strahovyh organizacij // Postkrizisnye orientiry social'no-jekonomicheskogo i innovacionnogo razvitija Kazahstana. 2010. Karaganda. https://articlekz.com

10. Averchenko O.D. (2017) Osnovnye instrumenty nejtralizacii riskov integracii bankov $i$ strahovyh kompanij.// Vestnik Moskva Un-ta. Ser. 6. Jekonomika, №1. 2017. -p. 101-122.

11. (2018) Znachimost' sistemy risk-menedzhmenta dlja strahovyh kompanij v rejtingovym analize. https://forinsurer.com

12. Jaranceva E.A. (2017) Metody ocenki riskov, vozdejstvujushhih na finansovuju ustojchivost' strahovyh organizacij: dissertacija kandidata jekonomicheskih nauk, 2017

13. Slepuhina Ju.Je. (2011) Kompleksnoe upravlenie riskami v strahovyh organizacijah. Diss. d-ra. jekon. nauk. Moskva, 2011. http://economy-lib.com

14. Gushterov D.H. (2006) Upravlenie riskom dejatel'nosti strahovoj kompanii. Diss. kand. jekon. nauk. Moskva, 2006.- 196 p.

15. Morozko N.I. (2007) Metodologija upravlenija finansami strahovoj sistemy. Diss. d-ra jekon. nauk. Moskva, 2007.- 411 p.

16. Finogenova Ju.Ju. (2012) Strahovoj riskmenedzhment personal'nyh investorov. Diss. dra jekon. nauk. Moskva, 2012.- 393 p.

17. Zadojannyj A.A. (2001) Kontrol' platezhesposobnosti $\mathrm{v}$ sisteme monitoringa strahovyh kompanij. Diss. kand. jekon. nauk. Sankt-Peterburg, 2001.- $181 \mathrm{p}$.

18. Bahcheeva M.N. (2009) Mehanizm snizhenija finansovyh riskov promyshlennogo predprijatija pri formirovanii strahovoj zashhity. Diss. kand. jekon. nauk. Orel, 2009.- 175 p. 